This article was downloaded by: [University of Toronto Libraries]

On: 19 November 2013, At: 08:23

Publisher: Routledge

Informa Ltd Registered in England and Wales Registered Number: 1072954 Registered office: Mortimer House, 37-41 Mortimer Street, London W1T 3J H, UK

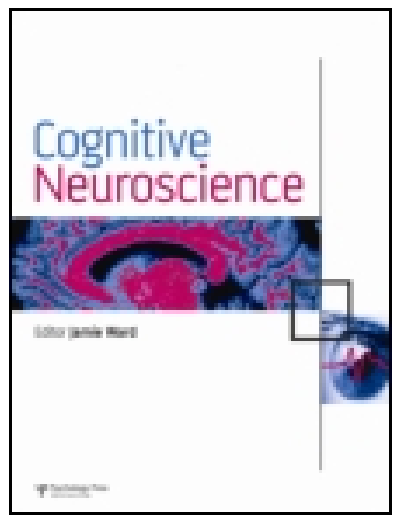

\title{
Cognitive Neuroscience
}

Publication details, including instructions for authors and subscription information:

http:// www. tandfonline.com/loi/ pens20

\section{Neural correlates of cognitive decline in older adults at-risk for developing MCl: Evidence from the CDA and P300}

Rachel N. Newsome ${ }^{a}$, Carson Pun ${ }^{a}$, Victoria M. Smith ${ }^{a}$, Susanne Ferber ${ }^{\text {ab }} \&$ Morgan D. Barense $^{\mathrm{ab}}$

a Department of Psychology, University of Toronto, Toronto, Canada

${ }^{\mathrm{b}}$ Rotman Research Institute, Toronto, Canada

Published online: 19 Nov 2013.

To cite this article: Rachel N. Newsome, Carson Pun, Victoria M. Smith, Susanne Ferber \& Morgan D. Barense (2013) Neural correlates of cognitive decline in older adults at-risk for developing $\mathrm{MCl}$ : Evidence from the CDA and P300, Cognitive Neuroscience, 4:3-4, 152-162

To link to this article: http:// dx. doi.org/ 10.1080/17588928.2013.853658

\section{PLEASE SCROLL DOWN FOR ARTICLE}

Taylor \& Francis makes every effort to ensure the accuracy of all the information (the "Content") contained in the publications on our platform. However, Taylor \& Francis, our agents, and our licensors make no representations or warranties whatsoever as to the accuracy, completeness, or suitability for any purpose of the Content. Any opinions and views expressed in this publication are the opinions and views of the authors, and are not the views of or endorsed by Taylor \& Francis. The accuracy of the Content should not be relied upon and should be independently verified with primary sources of information. Taylor and Francis shall not be liable for any losses, actions, claims, proceedings, demands, costs, expenses, damages, and other liabilities whatsoever or howsoever caused arising directly or indirectly in connection with, in relation to or arising out of the use of the Content.

This article may be used for research, teaching, and private study purposes. Any substantial or systematic reproduction, redistribution, reselling, loan, sub-licensing, systematic supply, or distribution in any form to anyone is expressly forbidden. Terms \& Conditions of access and use can be found at http:// www.tandfonline.com/page/terms-and-conditions 


\title{
Neural correlates of cognitive decline in older adults at-risk for developing $\mathrm{MCl}$ : Evidence from the CDA and P300
}

\author{
Rachel N. Newsome ${ }^{1}$, Carson Pun ${ }^{1}$, Victoria M. Smith ${ }^{1}$, Susanne Ferber ${ }^{1,2}$, \\ and Morgan D. Barense ${ }^{1,2}$ \\ ${ }^{1}$ Department of Psychology, University of Toronto, Toronto, Canada \\ ${ }^{2}$ Rotman Research Institute, Toronto, Canada
}

\begin{abstract}
Improving the ability to detect Alzheimer's disease (AD) at the earliest stages is essential to effectively treat afflicted individuals. Electrophysiological signatures are a promising avenue for earlier diagnosis. In the present study, we investigated an ERP component associated with visual working memory capacity, the contralateral delay activity (CDA). Our participants were undiagnosed and supposedly healthy members of the community, but were defined to be at-risk for Mild Cognitive Impairment (MCI) based on performance from a brief, standardized neuropsychological test. We found that older adults at-risk for MCI had a reduced visual working memory capacity and reduced differentiation of the CDA. In a second experiment, we found that the P300, a wellcharacterized ERP component shown to be useful in determining conversion from MCI to AD, showed reduced amplitude in our at-risk group. Together, these findings suggest that electrophysiological signatures may be especially sensitive markers of the very earliest stages of AD.
\end{abstract}

Keywords: Alzheimer's disease; Mild cognitive impairment; Aging; EEG; Contralateral delay activity.

Mild Cognitive Impairment (MCI) is a disorder associated with increased risk for developing Alzheimer's disease (AD, Petersen, 2004). As more modifying therapies become available, it is of paramount importance to elucidate preclinical markers of this disease, so that treatment can be initiated as soon as possible. Recently, we found that older adults recruited from the community with no MCI diagnosis, but who fell below normative means on a standardized neuropsychological test developed to screen for MCI (the Montreal Cognitive Assessment, (MoCA) Nasreddine et al., 2005), showed behavioral impairments similar to patients with diagnosed MCI (Newsome, Duarte, \& Barense, 2012). It is unknown whether these preclinical, but at-risk, participants would show a similar neural signature to that associated with MCI. In the current study, we investigated two ERP correlates of behavior - the contralateral delay activity (CDA) and the $\mathrm{P} 300$ - in a group of fully-functioning older adults from the community who had no MCI diagnosis, but who are at-risk for MCI based on their MoCA performance. The P300 is a well-established component known to be associated with diagnosis of $\mathrm{MCI} / \mathrm{AD}$ (Lai, Lin, Liou, \& Liu, 2010) whereas to our knowledge, the CDA has never been investigated in an $\mathrm{MCI} /$ $\mathrm{AD}$ population.

The CDA has been characterized as an online signature of visual working memory (VWM) involvement (Vogel \& Machizawa, 2004). This component emerges about $300 \mathrm{~ms}$ into the task as a sustained,

Correspondence should be addressed to: Rachel Newsome, Department of Psychology, University of Toronto, 100 St. George Street, Toronto, Ontario, Canada M5S 3G3. E-mail: rachel.newsome@utoronto.ca

This research was supported by Canadian Institutes of Health Research (CIHR) grants to S.F. [106436] and M.D.B. [115148]. The authors would like to thank all participants for their involvement, and Nicholas Rule for helpful statistical discussions. 
negative-going activity over posterior electrode sites. It is typically assessed with a visual change-detection task, in which a limited number of simple visual stimuli have to be maintained in working memory over a brief delay. CDA amplitude during this delay predicts VWM capacity. That is, the amplitude of the CDA waveform increases with each additional item held in VWM, until a participant's individual VWM capacity is reached. Once capacity has been reached, the CDA amplitude no longer differentiates between higher set sizes. The CDA likely originates from several coordinated frontal and parietal sources, which are considered to be two nodes in the neural networks regulating working memory, selective attention, and executive functions (Constantinidis \& Procyk, 2004). Specifically, the prefrontal cortex is thought to play a role in both top-down attentional control as well as VWM maintenance and consolidation (Awh, Vogel, \& Oh, 2006; Postle, 2006) and patients with prefrontal lesions have demonstrated an abnormal CDA for the contralateral visual field (Voytek \& Knight, 2010). The posterior parietal cortex, however, is involved in the temporary storage of visual information and subserves shifts of attention to stimuli in the environment (Posner \& Dehaene, 1994; Robitaille, Grimault, \& Jolicouer, 2009; Todd \& Marois, 2004; Vogel \& Machizawa, 2004; Xu, 2002, 2007). It is well established that both brain areas are affected in MCI/AD (Mitolo et al., 2013; Nho et al., 2012), with corresponding deficits in VWM (AlescioLautier et al., 2007; Parra et al., 2009, 2010) and topdown control (Redel et al., 2010). Although it has been shown that older adults have reduced differentiation of the CDA relative to younger adults (Duarte et al., 2013; Jost, Bryck, Vogel, \& Mayr, 2011; Sander, Werkle-Bergner, \& Lindenberger, 2011), it is not known whether the CDA is affected in MCI. In the present study, we predicted that our at-risk group would show reduced differentiation of the CDA, reflecting a smaller VWM capacity.

In contrast to the recently discovered CDA, the P300 is one of the most commonly studied ERP components. It is characterized by a positive deflection with a latency between 250 and $500 \mathrm{~ms}$ and is most pronounced after infrequent (odd) auditory stimuli. P300 amplitude is thought to reflect the amount of attentional resources required to match the current stimulus with the representation of an earlier stimulus held in working memory (Donchin, 1981; Polich, 2007). The $P 300$ has a broad range of clinical applications and is known to be associated with the clinical diagnosis of MCI/AD (Lai et al., 2010). Although the P300 reflects some aspect of working memory engagement, its precise role remains elusive
(Donchin, 1981; Polich \& Kok, 1995). One putative neural generator of the P300 is the temporal parietal cortex (Barry \& Rushby, 2006), a region known to be affected by AD (Braak \& Braak, 1991).

A recent study utilized a simple, auditory oddball paradigm in $\mathrm{AD}$ and $\mathrm{MCI}$ patients and found that the P300 amplitude was reduced and latency was delayed in both patient groups at both original test and at a one-year follow-up, suggesting that this physiological marker occurs before diagnosis of AD (Lai et al., 2010). Interestingly, Ally and colleagues found that healthy and cognitively intact biological children of AD patients also had a reduced P300 amplitude and delayed latency (Ally, Jones, Cole, \& Budson, 2006). Importantly, these relatives of $\mathrm{AD}$ patients were healthy and cognitively intact, but their P300 was still abnormal. Together, these findings suggest that the P300 may serve as a robust measure of AD risk, and here, we predicted that in our at-risk group, P300 amplitude would be reduced and latency would be delayed.

In summary, the existing literature suggests that two ERP components, the CDA and the P300, might be sensitive to preclinical MCI. To test this, we investigated a group of fully functioning older adults recruited from the community who did not meet MCI diagnostic criteria (Petersen et al., 1999), but in whom neuropsychological screening indicated risk for developing MCI. We administered two ERP tasks: (1) a VWM task during which we measured the CDA and (2) an auditory oddball task during which we measured the P300. We predicted that relative to older and younger adult controls, the at-risk group would have less differentiation of the CDA and an aberrant P300.

\section{METHODS}

\section{Participants}

We recruited 13 younger adults from the Toronto community. Of these, one was excluded from data analysis due to EEG technical failure, leaving 12 remaining participants (nine female, $M_{\text {age }}=24.33$ years, $S D=3.47, M_{\text {education }}=15.97$ years, $S D=1.44$, all right-handed). We also recruited 27 older adults from the Adult Volunteer Pool at the University of Toronto, a database of over 3000 older adult participants. Of these, two were excluded for excessive EEG noise (more than $34 \%$ of trials rejected). Based on their MoCA scores, we classified the remaining 25 participants as either "healthy" $(n=13$, passing MoCA score: $\geq 26$, eight female, $M_{\text {age }}=69.54$ years, $S D=6.30, M_{\text {education }}=16.23$, 
$S D=3.81$, all right-handed), or "at-risk" ( $n=12$, failing MoCA score: $\leq 25$, seven female, $M_{\text {age }}=73$ years, $S D=5.86, M_{\text {education }}=16.45, S D=4.36$, two left-handed). The older adult groups were matched for age, $t(23)=1.42, p=.17$, and all groups were matched for education $t \mathrm{~s}<.27, \mathrm{ps}>.79$.

To create groups of equal numbers, we recruited older adults who had previously been randomly selected from the Adult Volunteer Pool and whose MoCA score was known, but importantly, the experimenter was blinded to those scores. At the conclusion of the experimental task, a new version of the MoCA was administered, which is reported here (see Table 1). All participants reported normal or corrected-to-normal vision, no psychiatric/neurological disorders (e.g., Parkinson's disease, AD, epilepsy, stroke, multiple sclerosis), no current psychoactive drug use, no past cerebrovascular incident, and no CNS-active medications. Participants in the present study did not express a subjective memory complaint. All participants lived independently and arrived at the lab on their own. All participants provided informed consent and were compensated for their time. The study was approved by the University of Toronto Ethics Review Board.

\section{NEUROPSYCHOLOGICAL BATTERY}

To further assess the cognitive profile of the at-risk group, 11 of the 12 at-risk participants returned for a thorough neuropsychological assessment within one year of original experimental testing. The battery consisted of the Logical Memory subtest from the Wechsler Memory Scale (Wechsler, 2009), Trails A\&B (Reitan \& Wolfson, 1985), the Digit Span subtest of the Wechsler Adult Intelligence Scale (Wechsler, 2008), the Rey-Osterreith Complex Figure (Osterreith, 1944), the Wechsler Abbreviated Scale of Intelligence (Wechsler, 1999), and the Visual Object and Space Perception Battery (Warrington \& James, 1991). Results are shown in Table 1. Relative to established norms, the at-risk group was not significantly impaired on any of these measures. However, consistent with the well-established episodic memory impairments in early MCI/AD (Hodges, 2000; Petersen et al., 1999) and impaired executive function (Ashendorf et al., 2008; Greenlief, Margolis, \& Erker, 1985), the at-risk participants were in the lowest quartile on some measures of episodic recall and Trails B. Thus, although they did not meet diagnostic criteria for $\mathrm{MCI}$ - they had neither subjective nor objective memory impairments (Petersen et al., 1999)_available neuropsychological evidence indicates that their memory is in the low average range and that they may be on the trajectory to MCI.

\section{Design and procedure}

\section{Memory capacity estimate}

Prior to the CDA task, VWM capacity was estimated using a change-detection task (Vogel, Woodman, \& Luck, 2001). Participants were asked to maintain one to six uniquely colored squares over a $1200 \mathrm{~ms}$ delay period, and to indicate whether any changes occurred between the sample and test arrays. Thirty trials were presented per set size (180 trials total). EEG was not recorded during this task. Memory capacity $(K)$ was estimated by applying the following formula: $K=$ set size $\times$ (hits-false alarms) (Cowan, 2001; Pashler, 1988). A participant's highest score of all set sizes reflected the memory capacity estimate. This task took approximately 10 minutes.

\section{$C D A$}

Each trial began with a centrally presented left- or right-facing arrow appearing $2^{\circ}$ above the fixation cross (see Figure 1). Participants focused their attention in the direction of the arrow, while maintaining central fixation. Following a 300-400 ms delay, a memory array consisting of between one and four colored squares on each side of the visual field was presented for $200 \mathrm{~ms}$. Following a $900 \mathrm{~ms}$ fixation cross, the probe display containing only one square in each hemifield appeared until participants indicated if the probed object on the cued side had changed color. Trials were self-paced, and participants were able to take a break to blink after every trial. Participants were allowed to practice until they felt comfortable with the task. The CDA task took approximately 30 minutes.

\section{P300}

We administered an auditory oddball task with procedures identical to Lai and colleagues (Lai et al., 2010). Participants indicated whether each $20 \mathrm{~ms}$ pure tone burst $(0 \mathrm{~ms}$ rise/fall time $)$ was a low tone $(1000 \mathrm{~Hz}$, standard trials) or a high tone (2000 Hz, oddball trials) with one of two keyboard responses. There were 600 trials in total (500 standard, 100 oddball). The bursts were presented at a variable interstimulus interval of 1-2 seconds. Trials were placed in blocks of five, after which the participant took a self-paced blink break. Stimuli were 
TABLE 1

Neuropsychological battery. Demographic information, and average raw scores for the neuropsychological battery administered to the at-risk group

\begin{tabular}{|c|c|c|c|}
\hline Measure & $\begin{array}{l}\text { At-risk Older Adults } \\
\quad\left(n=12^{*}\right)\end{array}$ & $\begin{array}{l}\text { Healthy Older } \\
\text { Adults }(n=13)\end{array}$ & $\begin{array}{l}\text { Younger Adults } \\
\quad(n=12)\end{array}$ \\
\hline Age & $73.00(5.86)$ & $69.53(6.31)$ & $24.33(3.47)$ \\
\hline Education & $16.45(4.36)$ & $16.23(3.81)$ & $15.97(1.44)$ \\
\hline MoCA & $22.9(1.73)$ & $27.9(1.55)$ & $28.8(1.40)$ \\
\hline$K$-estimate & $2.38(0.56)$ & $3.06(0.83)$ & $3.55(0.61)$ \\
\hline P300 Accuracy & $0.96(0.04)$ & $0.95(0.04)$ & $0.94(0.06)$ \\
\hline $\operatorname{MoCA}(/ 30)$ & $23.00(1.65)$ & $27.77(1.42)$ & $28.54(1.29)$ \\
\hline Visuospatial/Executive (/5) & $2.75(1.36)$ & $4.23(0.93)$ & $4.91(0.30)$ \\
\hline Naming (/3) & $2.50(0.52)$ & $3(0)$ & $3(0)$ \\
\hline Attention (/6) & $5.42(0.79)$ & $5.85(0.38)$ & $5.73(0.65)$ \\
\hline Language $(/ 3)$ & $2.50(0.90)$ & $2.85(0.38)$ & $3(0)$ \\
\hline Abstraction (/2) & $1.75(0.45)$ & $2(0)$ & $2(0)$ \\
\hline Delayed Recall (/5) & $2.17(1.40)$ & $3.77(1.17)$ & $3.91(1.04)$ \\
\hline Orientation $(/ 6)$ & $5.83(0.39)$ & $6(0)$ & $6(0)$ \\
\hline WMS-IV LM Immediate Recall & $\begin{array}{l}31.82(9.62) \\
58 \% \text { tile, Average }\end{array}$ & - & - \\
\hline WMS-IV LM Delayed Recall (20 min delay) & $\begin{array}{l}18.45(6.41) \\
39 \% \text { tile, Average }\end{array}$ & - & - \\
\hline WMS-IV LM Recognition & $\begin{array}{l}19.91(2.34) \\
60 \% \text { tile, Average }\end{array}$ & - & - \\
\hline Rey Copy & $\begin{array}{l}25.05 \text { ( } 7.27) \\
17 \% \text { tile, Low Average }\end{array}$ & - & - \\
\hline Rey Immediate Recall & $\begin{array}{l}10.86(6.17) \\
21 \% \text { tile, Low Average }\end{array}$ & - & - \\
\hline Rey Delayed Recall (30 min delay) & $\begin{array}{l}9.27(5.84) \\
14 \% \text { tile, Low Average }\end{array}$ & - & - \\
\hline WASI Vocabulary & $\begin{array}{l}60.73(9.57) \\
73 \% \text { tile, Average }\end{array}$ & - & - \\
\hline WASI Similarities & $\begin{array}{l}38.91 \text { (2.84) } \\
88 \% \text { tile, High Average }\end{array}$ & - & - \\
\hline WASI Matrix Reasoning & $\begin{array}{l}20(6.93) \\
75 \% \text { tile, Average }\end{array}$ & - & - \\
\hline WASI Block Design & $\begin{array}{l}23.91(10.74) \\
47 \% \text { tile, Average }\end{array}$ & - & - \\
\hline VOSP: Shape Detection & $\begin{array}{l}19.00 \\
\text { Pass }\end{array}$ & - & - \\
\hline VOSP: Incomplete Letter & $\begin{array}{l}19.45 \\
\text { Pass }\end{array}$ & - & - \\
\hline VOSP: Silhouettes & $\begin{array}{l}18.18 \\
\text { Pass }\end{array}$ & - & - \\
\hline VOSP: Object Decision & $\begin{array}{l}15.91 \\
\text { Pass }\end{array}$ & $\begin{array}{l}- \\
-\end{array}$ & $\begin{array}{l}- \\
-\end{array}$ \\
\hline VOSP: Progressive Silhouettes & $\begin{array}{l}10.45 \\
\text { Pass }\end{array}$ & - & - \\
\hline VOSP: Dot Counting & $\begin{array}{l}9.64 \\
\text { Pass }\end{array}$ & - & - \\
\hline VOSP: Position Discrimination & $\begin{array}{l}18.82 \\
\text { Pass }\end{array}$ & & \\
\hline VOSP: Number Location & $\begin{array}{l}8.27 \\
\text { Pass }\end{array}$ & - & - \\
\hline
\end{tabular}


TABLE 1

(Continued)

\begin{tabular}{|c|c|c|c|}
\hline Measure & $\begin{array}{l}\text { At-risk Older Adults } \\
\qquad\left(n=12^{*}\right)\end{array}$ & $\begin{array}{l}\text { Healthy Older } \\
\text { Adults }(n=13)\end{array}$ & $\begin{array}{c}\text { Younger Adults } \\
\quad(n=12)\end{array}$ \\
\hline VOSP: Cube Analysis & $\begin{array}{l}8.18 \\
\text { Pass }\end{array}$ & - & - \\
\hline Trails A & $\begin{array}{l}49.27(26.02) \\
38 \% \text { tile, Average }\end{array}$ & - & - \\
\hline Trails B & $\begin{array}{l}130.36(58.67) \\
21 \% \text { tile, Low Average }\end{array}$ & - & - \\
\hline Digit Span Forward & $\begin{array}{l}7.55(2.73) \\
\text { Normal range }\end{array}$ & - & - \\
\hline Digit Span Backward & $\begin{array}{l}5.09(1.70) \\
\text { Normal range }\end{array}$ & - & - \\
\hline
\end{tabular}

Notes: * for the neuropsychological battery, $n=11$. Maximum and cut-off scores are listed in parentheses. Standard deviations $(S D \mathrm{~s})$ are indicated in parentheses next to the average raw scores. Percentile scores for the group average relative to established norms are shown when available.

WMS-IV LM $=$ Wechsler Memory Scale, 4 th edition, Logical Memory Subtest.

Rey $=$ Rey-Osterreith Complex Figure Test.

WASI $=$ Wechsler Abbreviated Scale of Intelligence.

VOSP $=$ Visual Object and Space Battery.

presented through Sennheiser headphones at $80 \mathrm{~dB}$ SPL. All participants exhibited normal hearing sensitivity at audiometric frequencies between 1000 $2000 \mathrm{~Hz}$. There was a short practice of 20 trials with feedback. There was no further feedback for the experimental task. The P300 task took approximately 30 minutes.

\section{EEG processing and ERP analysis}

Scalp-recorded EEG data were collected from $64 \mathrm{Ag}$ $\mathrm{AgCL}$ electrodes using an Active Two amplifier system (BioSemi, Netherlands). Electrodes were placed according to the 10-20 standard system, and all were referenced offline to two additional electrodes placed on bilateral mastoid processes. Two supplementary electrodes were placed on the outer canthi of the left and right eyes in order to record the horizontal electrooculogram, and two more leads were placed below the left and right eyes to record the vertical electrooculogram. EEG was recorded with 24-bit resolution and a sampling rate of $512 \mathrm{~Hz}$. Offline data were downsampled to $256 \mathrm{~Hz}$ and digitally filtered between $0.1 \mathrm{~Hz}$ and $30 \mathrm{~Hz}$.

All ERP processing was conducted in Matlab (Version R2011) using the EEGLAB Toolbox (Version 2.0, Delorme \& Makeig, 2004) and the ERPLAB Toolbox (Version 10.2.5.5). Epochs containing any eyeblink artifacts (more than $80 \mu \mathrm{V}$ of peak-to-peak amplitude) and horizontal eye movements (more than $35 \mu \mathrm{V}$ of step-like artifacts) were automatically removed. Trial rejection numbers did not differ for any of the groups (at-risk, $\mathrm{M}_{\text {rejection }}=13.34, S D=12.12$, vs. healthy older adult, $\mathrm{M}_{\text {rejection }}=7.83, S D=10.44: t(23)=1.22, p=.23$; healthy older adult vs young adult, $\mathrm{M}_{\text {rejection }}=4.89, S D=3.66: t$ $(23)=.93, p=.36)$. EEG segments of $1100 \mathrm{~ms}$ including $200 \mathrm{~ms}$ of pre-stimulus baseline, time-locked to stimulus onset, were created and averaged separately for each participant, electrode, and condition. All epochs were baseline corrected and amplitudes were measured relative to the $200 \mathrm{~ms}$ baseline.

\section{$C D A$}

We assessed the CDA from $300-800 \mathrm{~ms}$ following onset of the memory array. We calculated the mean amplitude for each participant in each set size $(1,3,4)$ of the CDA component for correct trials only. ERPs were analyzed from the three sites $(\mathrm{CP} 3 / \mathrm{CP} 4, \mathrm{PO} 7 /$ PO8, P5/P6) (Jost et al., 2011; Sander et al., 2011). Based on previous research (Duarte et al., 2013; Jost et al., 2011; Sander et al., 2011), we predicted young adults would have greater CDA differentiation and a higher VWM capacity than healthy older adults. Most importantly, we predicted that healthy older adults would have more CDA differentiation and a higher $K$-estimate than the at-risk older adults.

\section{P300}

We assessed the P300 as the latency window between $300-500 \mathrm{~ms}$ after stimulus onset and calculated the peak amplitude and latency for each 


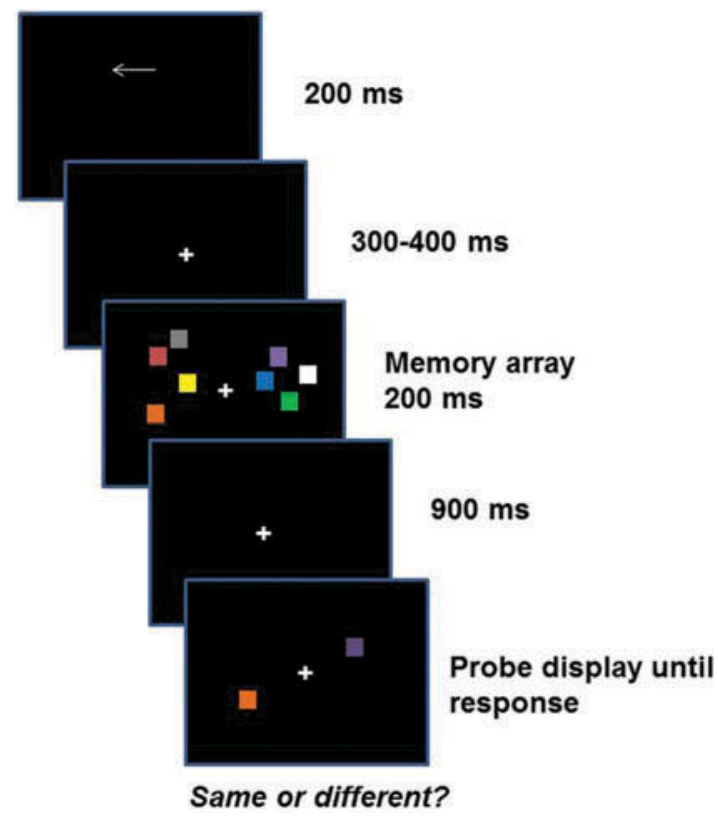

Figure 1. Task Schematic of a single trial from the changedetection task. Participants were instructed to shift their attention to the arrow-cued side for the remainder of the trial while fixating on the central cross. Participants pressed a button to indicate whether the object shown on the cued side of the probe display had changed color. This is an example of a "same" trial, because the probed square is orange in both the memory array and the probe. ERP analyses were time-locked to the onset of the memory array.

participant. Consistent with previous experiments using similar paradigms, ERPs were analyzed from three electrode sites (Fz, Cz, Pz) (e.g., Ally et al., 2006). We predicted that the at-risk group would have reduced P300 amplitude and delayed latency relative to healthy older adults.

\section{Data analysis}

All analyses were performed with the ANOVAs described below. Because we were interested in effects of aging and effects of preclinical MCI, we restricted follow-up tests to comparisons between young adults vs. healthy older adults, and healthy older adults vs. at-risk older adults. For all analyses, $p$-values and degrees of freedom reflect the Greenhouse-Geisser correction where appropriate.

\section{Results}

Behavioral results: Memory capacity estimate

Maximum $K$-estimates from the memory capacity estimate task are shown in Table 1. The healthy older adult group had a significantly larger $K$-estimate than the at-risk group, $t(23)=2.36, p=.03$. Although numerically the young adults had a larger capacity than the healthy older adults, this difference was not significant, $t(23)=-23) p=.11$. Interestingly, this is inconsistent with previous literature showing that healthy older adults have a reduced short-term memory capacity (Verhaeghen \& Salthouse, 1997), suggesting that perhaps by using the sensitive MoCA to exclude at-risk participants from the healthy older adult control group, we have a control sample uncontaminated by early-stage MCI.

\section{Behavioral results: CDA task}

We conducted a 3 (group) $\times 3$ (set size) mixeddesign ANOVA on the behavioral $K$-estimates from the CDA task. This revealed a main effect of set size, $F(1.14,38.61)=126.50, p<.001, \eta_{\mathrm{p}}{ }^{2}=.79$, a main effect of group, $F(2,34)=4.52, p=.02, \eta_{\mathrm{p}}{ }^{2}=.21$, and a marginal set size $\times$ group interaction, $F(2.27$, $38.61)=2.82, p=.06, \eta_{\mathrm{p}}{ }^{2}=.14$. To investigate what was driving the set size $\times$ group marginal interaction, we conducted two separate 2 (group) $\times 3$ (set size) ANOVAs, in which our group factor was either at-risk older adults vs. healthy older adults or healthy older adults vs. young adults. The ANOVA comparing healthy older adults vs. at-risk older adults showed significant main effects of set size, $F(1.17$, $27.01)=64.22, p<.001, \eta_{\mathrm{p}}^{2}=.74$, and group, $F$ $(1,23)=4.18, p=.05, \eta_{\mathrm{p}}{ }^{2}=.15$, with no significant interaction, $F(1.17,27.01)=1.75, p=.20, \eta_{\mathrm{p}}^{2}=.07$, indicating that, overall, performance in the at-risk group was lower than in the healthy older adults. However, the ANOVA comparing young vs. older adults showed only a significant main effect of set size, $F(1.04,23.94)=142.36, p<.001, \eta_{\mathrm{p}}{ }^{2}=.86$, but no other significant effects or interactions, $F$ 's $<1.69$, $p \mathrm{~s}>.21, \eta_{\mathrm{p}}{ }^{2} \mathrm{~s}<.07$, suggesting performance between the young and older adult groups was not significantly different.

\section{ERP results: $C D A$}

We conducted a 3 (group) $\times 3$ (electrode) $\times 3$ (set size) mixed-design ANOVA on the CDA data (see Figure 2). This revealed a main effect of set size, $F(2$, $68)=25.09, p<.001, \eta_{\mathrm{p}}{ }^{2}=.43$, an electrode $\times$ group interaction, $F(2.82,47.90)=2.86, p=.05, \eta_{\mathrm{p}}{ }^{2}=.14$, and a set size $\times$ group interaction, $F(4,68)=3.41$, $p=.01, \eta_{\mathrm{p}}{ }^{2}=.17$. There were no other significant effects or interactions, $F \mathrm{~s}<1.31, p \mathrm{~s}>.27, \eta_{\mathrm{p}}{ }^{2} \mathrm{~s}<.07$, which importantly included no three-way interaction of set size $\times$ electrode $\times$ group, $F(4.69,79.73)=1.31$, 
$p=.27, \eta_{\mathrm{p}}{ }^{2}=.07$, thus justifying collapsing across electrode site in subsequent analyses. To investigate the nature of the set size $\times$ group interaction, we conducted two separate 2 (group) $\times 3$ (set size) ANOVAs, in which our group factor was either atrisk older adults vs. healthy older adults or healthy older adults vs. young adults, so that we could directly investigate effects of preclinical MCI and effects of aging. Critically, the comparison of at-risk older adults vs. healthy older adults showed a significant set size $\times$ group interaction, $F(1.70$, $39.09)=4.05, p=.02, \eta_{\mathrm{p}}{ }^{2}=.15$, indicating that the degree of differentiation across set size differed between at-risk adults and their controls. However, the healthy older adults vs. young adult comparison showed no set size $\times$ group interaction $F(1.91$, 43.89) $=1.11, p=.34, \eta_{\mathrm{p}}^{2}=.05$, suggesting there was no variance in differentiation between the young and healthy older adult groups. These findings correspond to the behavioral findings described above: There were no behavioral or physiological differences between the young and older adults, yet the at-risk older adults showed lower behavioral performance as well as reduced electrophysiological differentiation, compared to healthy older adults. There were no effects or interactions with electrode in the at-risk older adult vs. healthy older adult ANOVA, $F$ s $<1.30, p \mathrm{~s}>.28, \eta_{\mathrm{p}}{ }^{2} \mathrm{~s}<.05$. The healthy older adult vs. young adults ANOVA revealed a main effect of electrode, $F(1.46,33.66)=4.01, p=.04, \eta_{\mathrm{p}}{ }^{2}=.15$ and a marginal electrode $\times$ group interaction, $F(1.46$, $33.66)=2.73, p=.09, \eta_{\mathrm{p}}{ }^{2}=.11$. There were no other significant interactions, $F_{\mathrm{s}}<1.61, p \mathrm{~s}>.21, \eta_{\mathrm{p}}{ }^{2} \mathrm{~s}<.07$.

To further investigate differentiation within each group, we then performed individual 3 (set size) $\times 3$ (electrode) repeated-measures ANOVAs within each group. For young adults, this revealed a significant main effect of set size, $F(2,22)=11.95, p<.001$,
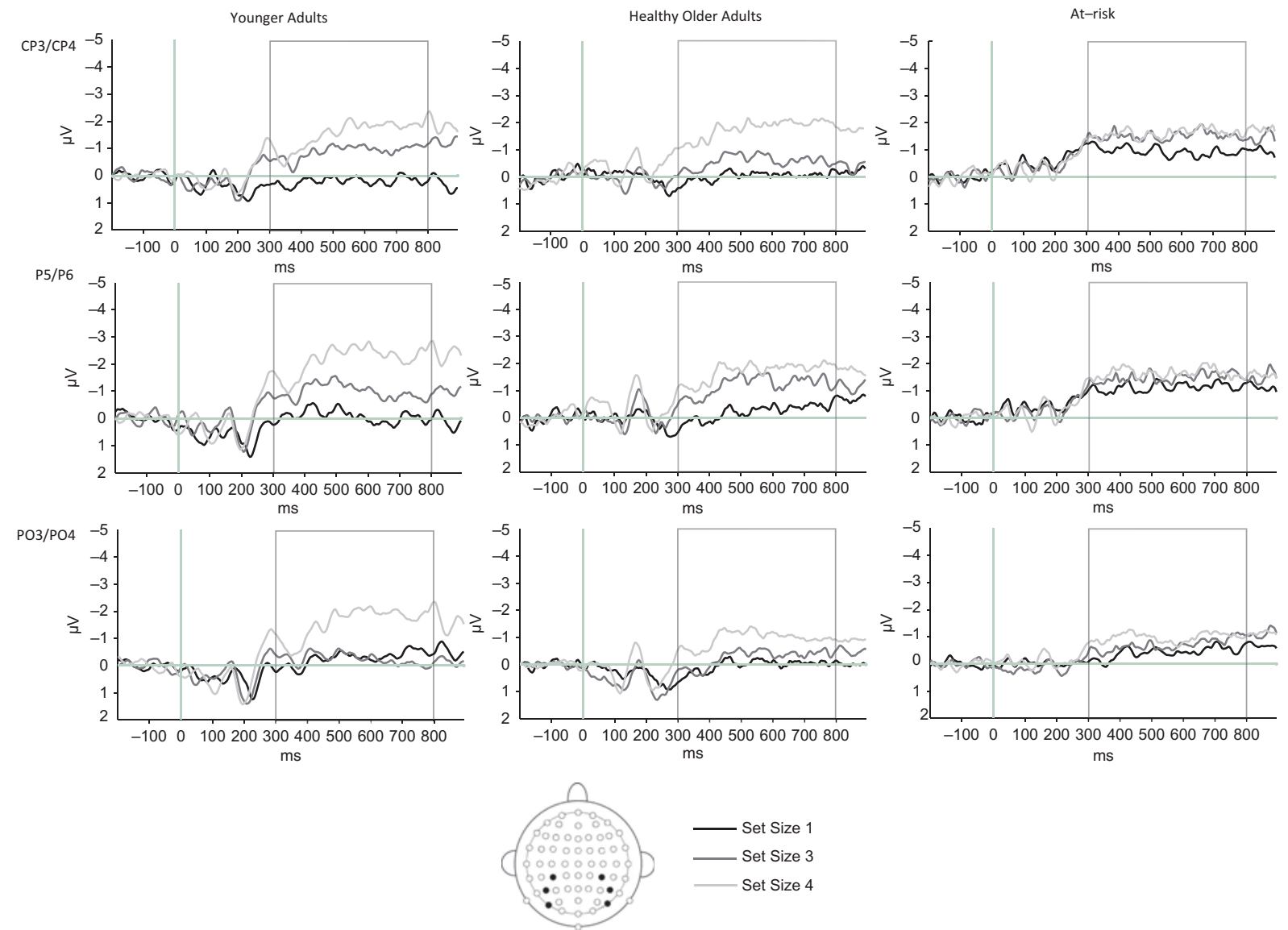

Figure 2. CDA Event related potentials from the contralateral delay activity (CDA) in the younger adults $(N=12)$, healthy older adults $(N=13)$, and at-risk older adults $(N=12)$. We calculated the CDA by subtracting ipsilateral from contralateral activity, time-locked to the onset of the memory array. We analyzed activity from six electrode sites, CP3/CP4, P5/P6, and PO7/PO8 during the 300-800 ms latency window indicated by the gray box. We found that at-risk participants showed reduced differentiation of the CDA. By contrast, both healthy younger and older control groups showed differentiation at all set sizes. 
$\eta_{\mathrm{p}}^{2}=.52$, and pairwise comparisons between each set size were significant for 1 vs. $4(p<.001), 3$ vs. 4 $(p=.02)$, and marginal for 1 vs. $3(p=.06)$. The ANOVA also revealed a marginal main effect of electrode for the younger adult group, $F(1.30$, $14.27)=3.82, p=.06, \eta_{\mathrm{p}}{ }^{2}=.26$. For older adults, the ANOVA revealed a main effect of set size, $F(2$, $24)=21.69, p<.001, \eta_{\mathrm{p}}{ }^{2}=.64$, and pairwise comparisons between each set size were all significant, $p \mathrm{~s}<.02$. There were no main effects or interactions with electrode in the healthy older adult group, $F_{\mathrm{S}}$ $<2.0, p \mathrm{~s}>.12, \eta_{\mathrm{p}}{ }^{2} \mathrm{~s}<.14$. In contrast to young and healthy older adults, there was no effect of set size in the at-risk group, $F(2,22)=1.61, p=.23, \eta_{\mathrm{p}}{ }^{2}=.13$, indicating that the at-risk participants did not show differentiation of the CDA as set size increased. There were no main effects or interactions with electrode in the at-risk group, $F_{\mathrm{s}}<.79, p \mathrm{~s}>.42, \eta_{\mathrm{p}}{ }^{2} \mathrm{~s}<.07$.

\section{Behavioral results: P300 oddball task}

Behavioral results of the $\mathrm{P} 300$ oddball task are shown in Table 1. There was no difference in accuracy between the at-risk group and healthy older adults, $t(23)=-23) p=.51$, or between healthy older adults and younger adults, $t(23)=1.08, p=.29$.

\section{ERP results: $P 300$ amplitude}

A 3 (group) $\times 3$ (electrode) mixed-design ANOVA was performed on the P300 peak amplitude data (see Figure 3 ). This revealed a marginally significant main effect of group, $F(2,34)=3.14, p=.056, \eta_{\mathrm{p}}{ }^{2}=.156$, a significant effect of electrode, $F(1.48,50.27)=5.08$, $p=.02, \eta_{\mathrm{p}}{ }^{2}=.13$, and a significant group $\times$ electrode interaction, $F(2.96,50.27)=6.91, p=.001, \eta_{\mathrm{p}}{ }^{2}=.29$. To investigate the group $\times$ electrode interaction, we performed follow-up independent samples $t$-tests at each electrode to compare the at-risk group vs. healthy older adults, and healthy older adults vs. younger adults. These revealed reduced P300 amplitude in the at-risk group at $\mathrm{Fz}, t(23)=-3) p=.05$, and marginally reduced amplitude at $\mathrm{Cz}, t(23)=-23$ ) $p=.065$, but no significant reduction at $\mathrm{Pz}$, $t(23)=-3) 5, p=.20$. Younger adults showed a larger amplitude than older adults at $\mathrm{Pz}, t(23)=-23)$ $p=.01$, but not at $\mathrm{Fz}, t(23)=1.46, p=.16$, or $\mathrm{Cz}$, $t(23)=-23) p=.37$.

\section{ERP results: $P 300$ latency}

The ANOVA described above was also conducted on the latency data. This revealed a main effect of electrode, $F(1.66,56.44)=8.02, p=.002, \eta_{\mathrm{p}}{ }^{2}=.19$. However, in contrast to our predictions and to previous studies (Lai et al., 2010; Papaliagkas, Kimiskidis, Tsolaki, \& Anogianakis, 2008; Polich, Ladish, \& Bloom, 1990), we found no other significant effects or interactions, $F \mathrm{~s}<2.04, p \mathrm{~s}>.15$, $\eta_{\mathrm{p}}^{2} \mathrm{~s}<.11$.

\section{GENERAL DISCUSSION}

To our knowledge, this study provides the first evidence of reduced differentiation of the CDA in a preclinical population who had no MCI diagnosis, but whose neuropsychological screening indicated risk for developing MCI. We found that, consistent with their VWM impairment, the at-risk group displayed an abnormal CDA, with no significant differentiation between set sizes. In a profile similar to that observed in cases with diagnosed MCI/AD (Lai et al., 2010), we found that these at-risk individuals also demonstrated some evidence for a reduced P300 amplitude.

The CDA is an ERP component thought to reflect the number of items currently being held in VWM, is reflective of individual capacity limit (Vogel \& Machizawa, 2004), and originates from several coordinated sources with a major hub in the parietal cortex (Robitaille et al., 2009; Todd \& Marois, 2004). Both parietal and frontal brain regions are thought to underlie top-down attentional control (Corbetta \& Shulman, 2002), and in fact, patients with prefrontal cortex damage have both behavioral impairments and an abnormal CDA pattern when stimuli are presented contralateral to the lesioned hemisphere (Voytek \& Knight, 2010). Thus, it is likely that the CDA amplitude is also influenced by top-down control, and may reflect the complexity of processing or an increase in complexity of the representations of the stimuli (Alvarez \& Cavanagh, 2004; Gao et al., 2009). One recent study found that $\mathrm{CDA}$ amplitude at $\mathrm{P} 1 / \mathrm{P} 2$ was sensitive to number of objects, whereas amplitude at another site, P7/P8 was sensitive to number of features (Wilson, Adamo, Barense, \& Ferber, 2012).

Although no published studies have investigated the effect of MCI/AD pathology on the CDA, there have been a few published studies investigating agerelated effects on the CDA. Older adults have a reduced CDA amplitude relative to younger adults (Duarte et al., 2013), as well as reduced differentiation of the CDA (Jost et al., 2011). Notably, however, in the current study, we did not find a behavioral or physiological effect of healthy aging on VWM in terms of $K$-estimates or CDA differentiation. That is, 

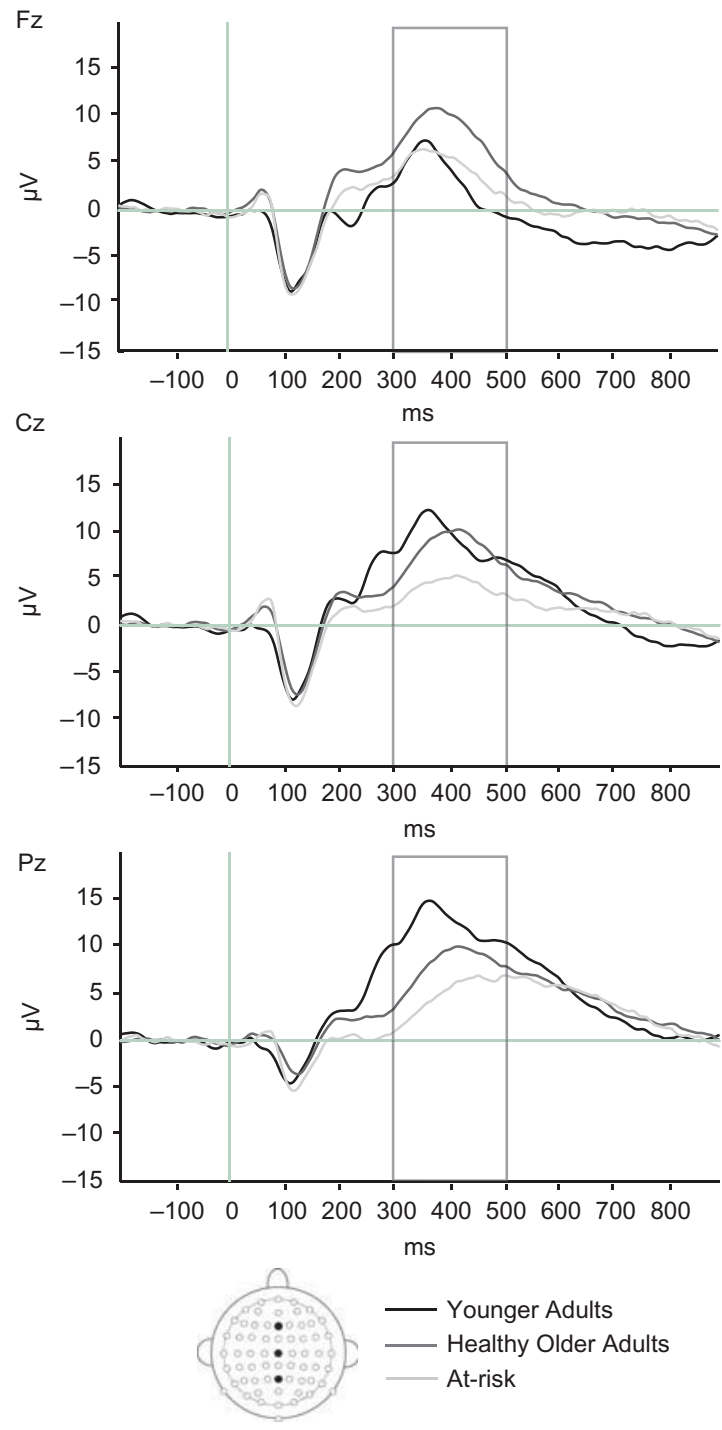

Figure 3. P300 Event related potentials from the P300 oddball condition in the younger adults $(N=12)$, healthy older adults $(N=13)$, and at-risk older adults $(N=12)$. We analyzed activity from three electrode sites $(\mathrm{Fz}, \mathrm{Cz}$, and $\mathrm{Pz}$ ) during the $300-500 \mathrm{~ms}$ latency window indicated by the gray box. We found that the P300 amplitude was significantly reduced in at-risk participants compared to healthy older adult control at $\mathrm{Fz}$, marginally reduced amplitude at $\mathrm{Cz}$, and not significantly different at $\mathrm{Pz}$.

healthy older adults were not impaired relative to young adults in terms of their $K$-estimate or their CDA differentiation. These results are in contrast to three previous studies examining aging in the CDA, which have all shown a reduced $K$-estimate for older adults and a reduced CDA amplitude for older adults (Duarte et al., 2013; Jost et al., 2011; Sander et al., 2011). In these past studies, older adults were not split according to level of cognitive decline. If we had not split our groups according to MoCA performance in the present study, we would likely have found deficits which we would have attributed to normal, cognitive aging rather than to pathological decline. This highlights the importance of using sensitive cognitive screening measures in studies of healthy aging to ensure that the sample of healthy older adults is uncontaminated with preclinical MCI.

By the same token, the fact that these at-risk participants were putatively healthy members of the community, who were randomly selected from a large volunteer subject panel and did not meet MCI diagnostic criteria, indicates that these electrophysiological signatures may be particularly sensitive to the earliest stages of the disease process. The true predictive power of these measures must be established in longitudinal studies that assess whether a given individual's electrophysiological profile is a better predictor of conversion to MCI/AD than a failing MoCA score. Such experiments are currently underway. EEGs are easily performed, inexpensive, and noninvasive, making this a promising and accessible method for preclinical screening. Identification of robust preclinical markers will hasten diagnosis, allowing for earlier treatment, future planning, and maximization of quality of life. In addition, future work should also explore whether changes in EEG power frequency are a promising new marker for detecting preclinical MCI (Hatz et al., 2013; Moretti, Zanetti, Binetti, \& Frisoni, 2012; Musha et al., 2013).

In conclusion, the present findings provide evidence that electrophysiological markers of shortterm memory and attention are altered in a preclinical group of older adults with no MCI diagnosis, but in whom neuropsychological screening indicated risk for developing MCI. Our results from these putatively healthy community-dwelling volunteers indicate that the CDA and P300 may be particularly sensitive to the earliest stage of the disease process.

\section{REFERENCES}

Alescio-Lautier, B., Michel, B., Herrera, C., Elahmadi, A., Chambon, C., Touzet, C., \& Paban, V. (2007). Visual and visuospatial short-term memory in mild cognitive impairment and Alzheimer's disease: Role of attention. Neuropsychologia, 45, 1948-1960.

Ally, B., Jones, G., Cole, J., \& Budson, A. (2006). The P300 component in patients with Alzheimer's disease and their biological children. Biological Psychology, $72,180-187$.

Alvarez, G., \& Cavanagh, P. (2004). The capacity of visual short-term memory is set both by information load and by number of objects. Psychological Science, 15, 106-111. 
Ashendorf, L., Jefferson, A., O’Connor, M., Chaisson, C., Green, R., \& Stern, R. (2008). Trail making test errors in normal aigng, mild cognitive impairment, and dementia. Archives of Clinical Neuropsychology, 23, 129-137.

Awh, E., Vogel, E., \& Oh, S. (2006). Interactions between attention and working memory. Neuroscience, 139, 201-208.

Barry, R., \& Rushby, J. (2006). An orienting reflex perspective on anteriorisation of the P3 of the eventrelated potential. Experimental Brain Research, 173, 539-545.

Braak, H., \& Braak, E. (1991). Neuropathological stageing of Alzheimer-related changes. Acta Neuropathologica, $82,239-259$

Constantinidis, C., \& Procyk, E. (2004). The primate working memory networks. Cognitive Affective \& Behavioral Neuroscience, 4(4), 444-465.

Corbetta, M., \& Shulman, G. (2002). Control of goal-directed and stimulus-driven attention in the brain. Nature Reviews Neuroscience, 3(3), 201-215.

Cowan, N. (2001). The magical number 4 in short-term memory: A reconsideration of mental storage capacity. Behav Brain Sci, 24, 87-114.

Delorme, A., \& Makeig, S. (2004). EEGLAB: An open source toolbox for analysis of single-trial EEG dynamics including independent component analysis. Journal of Neuroscience Methods, 134, 9-21.

Donchin, E. (1981). Surpise!...Surprise?. Psychophysiology, $18,493-513$.

Duarte, A., Hearons, P., Jiang, Y., Delvin, M., Newsome, R., \& Verhaeghen, P. (2013). Retrospective attention enhances visual working memory in the young but not the old: An ERP study. Psychophysiology, 50(5), 465-476.

EEGLAB (?.?) [Computer software]. http://sccn.ucsd.edu/ eeglab/.

EEGLAB (?.?) [Computer software]. http://software.incf. org/software/erplab-toolbox.

Gao, Z., Li, J., Liang, J., Chen, H., Yin, J., \& Shen, M. (2009). Storing fine detailed information in visual working memory - evidnece from event-related potentials. Journal of Vision, 9(7):17, 1-12. http://journalofvision. org/9/7/17/, doi:10.1167/9.7.17.

Greenlief, C., Margolis, R., \& Erker, G. (1985). Application of the trail making test in differentiating neuropsychological impairment of elderly persons. Perceptual and Motor Skills, 61, 1283-1289.

Hatz, F., Benz, N., Hardmeier, M., Zimmermann, R., Rueegg, S., Schindler, C., \& Fuhr, P. (2013). Quantitative EEG and apolipoprotein E-genotype improve classification of patients with suspected Alzheimer's disease. Clinical Neurophysiology, (124): 11, 2146-2152.

Hodges, J. (2000) Memory in the dementias. In E. Tulving \& F. Craik (Eds.), The oxford handbook of memory (pp. 441-459). Oxford, UK: Oxford University Press.

Jost, K., Bryck, R., Vogel, E., \& Mayr, U. (2011). Are old adults just like low working memory young adults? Filtering efficiency and age differences in visual working memory. Cerebral Cortex, 21, 1147-1154.

Lai, C. -L., Lin, R. -T., Liou, L. -M., \& Liu, C. -K. (2010). The role of event-related potentials in cognitive decline in Alzheimer's disease. Clinical Neurophysiology, 121, 194-199.
Matlab (?.?) [Computer software]. http://www.mathworks. co.uk/products/matlab/.

Mitolo, M., Gardini, S., Fasano, F., Crisi, G., Pelosi, A., Pazzaglia, F., \& Caffarra, P. (2013). Visuospatial memory and neuroimaging correlates in mild cognitive impairment. Journal of Alzheimer's Disease, 35, 75-90.

Moretti, D., Zanetti, O., Binetti, G., \& Frisoni, G. (2012). Quantitative EEG markers in mild cognitive impairment: Degenerative versus vascular brain impairment. International Journal of Alzheimer's Disease, 2012. dx.doi.org/10.1155/2012/917537

Musha, T., Matsuzaki, H., Kobayashi, Y., Okamoto, Y., Tanaka, M., \& Asada, T. (2013). EEG markers for characterizing anomalous activities of cerebral neurons in NAT (Neuronal Activity Topography) Method. IEEE Transaction on Biomedical Engineering, 60, 2332-2338.

Nasreddine, Z., Phillips, N., Bedirian, V., Charbonneau, S., Whitehead, V., Collin, I., \& Chertkow, H. (2005). The Montreal Cognitive Assessment, MoCA: A brief screening tool for mild cognitive impairment. Journal of American Geriatrics Society, 53, 695-699.

Newsome, R., Duarte, A., \& Barense, M. (2012). Reducing perceptual interference improves visual discrimination in mild cognitive impairment: Implications for a model of perirhinal cortex function. Hippocampus, 22, 1990-1999.

Nho, K., Risacher, S., Crane, P., DeCarli, C., Glymour, M., Habeck, C., \& Saykin, A. (2012). Voxel and surfacebased topography of memory and executive deficits in mild cognitive impairment and Alzheimer's disease. Brain Imaging and Behavior, 6(4), 551-567.

Osterreith, P. (1944). Filetest de copie d'une figure complex: Contribution a l'etude de la perception et de la memoire [The test of copying a complex figure: A contribution to the study of perception and memory]. Archives de Psychologie, 30, 286-356.

Papaliagkas, V., Kimiskidis, V., Tsolaki, M., \& Anogianakis, G. (2008). Usefulness of event-related potentials in the assessment of mild cognitive impairment. BMC Neuroscience, 9, 107.

Parra, M., Abrahams, S., Fabi, K., Logie, R., Luzzi, S., \& Della Sala, S. (2009). Short-term memory binding deficits in Alzheimer's disease. Brain, 132(4), 1057-1066.

Parra, M., Abrahams, S., Logie, R., Mendez, L., Lopera, F., \& Della Sala, S. (2010). Visual short-term memory binding deficits in familial Alzheimer's disease. Brain, 133(9), 2702-2713.

Pashler, H. (1988). Familiarity and visual change detection. Perception \& Psychophysics, 44, 369-378.

Petersen, R. (2004). Mild cognitive impairment as a diagnostic entity. Journal of Internal Medicine, 256, 183-194.

Petersen, R., Smith, G., Waring, S., Ivnik, R., Tangalos, E., \& Kokmen, E. (1999). Mild cognitive impairment: Clinical characterization and outcome. Archives of Neurology, 56, 303-308.

Polich, J. (2007). Updating P300: An integrative theory of P3a and P3b. Clinical Neurophysiology, 118(10), 2128-2148.

Polich, J., \& Kok, A. (1995). Cognitive and biological determinants of P300: An integrative review. Biological Psychology, 41, 103-146. 
Polich, J., Ladish, C., \& Bloom, F. (1990). P300 assessment of early Alzheimer's disease. Electroencephalography and clinical neurophysiology, 77, 179-189.

Posner, M., \& Dehaene, S. (1994). Attentional networks. Trends Neurosci, 17(2), 75-79.

Postle, B. (2006). Working memory as an emergent property of the mind and brain. Neuroscience, 139, 23-28.

Redel, P., Bublak, P., Sorg, C., Kurz, A., Forstl, H., Muller, H., \& Finke, K. (2010). Deficits of spatial and task-related attentional selection in mild cognitive impairment and Alzheimer's disease. Neurobiology of Aging, 33, 195.e27-42.

Reitan, R., \& Wolfson, D. (1985). The Halstead-Reitan neuropsychological test battery: Therapy and clinical interpretation. Tucson, AZ: Neuropsychological Press.

Robitaille, N., Grimault, S., \& Jolicouer, P. (2009). Bilateral parietal and contralateral responses during maintenance of unilaterally encoded objects in visual short-term memory: Evidence from magnetoencephalography. Psychophysiology, 46, 1090-1099.

Sander, M., Werkle-Bergner, M., \& Lindenberger, U. (2011). Contralateral delay activity reveals life-span age differences in top-down modulation of working memory contents. Cerebral Cortex, 21, 2809-2819.

Todd, J., \& Marois, R. (2004). Capacity limit of visual short-term memory in human posterior parietal cortex. Nature, 428, 751-754.

Verhaeghen, P., \& Salthouse, T. (1997). Meta-analyses of age-cognition relations in adulthood: Estimates of linear and nonlinear age effects and structural models. Psychological Bulletin, 122, 231-249.
Vogel, E., \& Machizawa, M. (2004). Neural activity predicts individual differences in visual working memory capacity. Nature, 428, 748-751.

Vogel, E., Woodman, G., \& Luck, S. (2001). Storage of features, conjunctions, and objects in visual working memory. Journal of Experimental Psychology: Human Perception and Performance, 27, 92-114.

Voytek, B., \& Knight, R. (2010). Prefrontal cortex and basal ganglia contributions to visual working memory. PNAS, 107, 18167-18172.

Warrington, E., \& James, M. (1991). Visual Object and Space Perception Battery (VOSP). Oxford, UK: Harcourt Assessment.

Wechsler, D. (1999). Wechsler abbreviated scale of intelligence. San Antonio, TX: Pearson.

Wechsler, D. (2008). Wechsler adult intelligence scale (4th Ed.). San Antonio, TX: Pearson.

Wechsler, D. (2009). Wechsler memory scale (4th Ed.). San Antonio, TX: Pearson.

Wilson, K., Adamo, M., Barense, M., \& Ferber, S. (2012). To bind or not to bind: Addressing the question of object representation in visual short-term memory. Journal of Vision, 12(8), 1-16.

$\mathrm{Xu}, \mathrm{Y}$. (2002). Encoding color and shape from different parts of an object in visual short-term memory. Perception and Psychophysics, 64, 1260-1280.

$\mathrm{Xu}, \mathrm{Y}$. (2007). The role of the superior intra-parietal sulcus in supporting visual short-term memory for multifeature objects. Journal of neuroscience, 27, 11676-11686. 